\title{
Ocular Problems in High-Altitude Traveling: A Review With Focus on Management
}

\author{
Morteza Izadi', Mohsen Pourazizi ${ }^{2,3}$, Mohammad-Hasan Alemzadeh-Ansari ${ }^{3 *}$ \\ ${ }^{1}$ Health Research Center, Baqiyatallah University of Medical Sciences, Tehran, Iran \\ ${ }^{2}$ Cancer Research Center, Semnan University of Medical Sciences, Semnan, Iran \\ ${ }^{3}$ Isfahan Eye Research Center, Department of Ophthalmology, Isfahan University of Medical Sciences, Isfahan, Iran \\ Corresponding Author: Mohammad-Hasan Alemzadeh-Ansari, M.D., Isfahan Eye Research Center, Department of \\ Ophthalmology, Isfahan University of Medical Sciences, Isfahan 81488-95185, Iran. Tel: +98916 607 8735, \\ Email: mh.aansari@gmail.com
}

Received December 29, 2016; Accepted February 22, 2017; Online Published May 30, 2017

\begin{abstract}
Traveling to high altitudes can expose the eye to reduced ambient cold and low-pressure environments. These conditions can affect the physiology of the eye and may result in ocular problems and visual disturbances. In this paper, ocular disorders related to high altitudes are briefly reviewed. Then, high-altitude ocular disorders are categorized in three parts: those related to dry and cold environments, those related to low-pressure environments, and those in people with past ocular conditions. In every part, the signs and symptoms of related diseases are discussed. Up-to-date recommendations for the management and prevention of these disorders are presented. The main management for ocular disorders related to dry and cold environments includes the use of eye shields and artificial tear drops. Descending to low-altitude lands is the key to managing eye problems associated with low-pressure environments. Patients with past ocular problems or ocular surgery should consult their doctors before ascending to high altitudes.
\end{abstract}

Keywords: Eye, Altitude, Travel, Ocular disorders

Citation: Izadi M, Pourazizi M, Alemzadeh-Ansari Mh. Ocular problems in high-altitude traveling: a review with focus on management. Int J Travel Med Glob Health. 2017;5(2):41-45. doi:10.15171/ijtmgh.2017.09.

\section{Introduction}

Exposure to cold and low-pressure environments during high-altitude traveling, whether during occupational or recreational activities, poses risks for cold-related or pressure-related injury to eyes. ${ }^{1}$ Furthermore, some preexisting ophthalmologic conditions may be exacerbated by high-altitude exposure. ${ }^{2}$ Visual disturbances may result from exposure to the hypoxia of high altitudes and cold environments.

The eyes are the primary interface with the environment. Despite technological advances that have allowed humans to live and travel in most of the environments on the planet, deliberate or inadvertent exposure to those environments may subject individuals to injury. ${ }^{3}$ Since such disorders are not common, only a minority of ophthalmologists are aware of the diagnoses.

The goal of this review is to familiarize sports medicine specialists and ophthalmologists with the management strategies of some ocular disorders related to high altitudes. For this purpose, high-altitude ocular disorders are categorized in three parts: those related to dry and cold environments, those related to low-pressure environment, and those in people with past ocular conditions. Finally, up-to-date recommendations for the management and prevention of these disorders are presented.

1-Eye Problems Associated With Dry and Cold Environments Acute Keratitis and Snow Blindness

The sun's ultraviolet radiation (UVR) is absorbed by the corneal and, cumulatively, can damage the corneal epithelium and cause acute keratitis. At high altitudes, acute keratitis is more common because of the increased UVR that reaches the earth and the presence of snow that has a highly reflective surface. ${ }^{4-6}$ Exposure to sun rays without protection at high altitudes usually causes an inflammatory disorder of the cornea known as snow blindness. Snow blindness is characterized by severe pain, redness, foreign body sensation in the eyes, tearing, photophobia, and decreased visual acuity. There is a lag time of about 6-12 hours between UVR exposure and the onset of these symptoms, so snow blindness is experienced by people going to mountains at night. ${ }^{7}$ Epiphora, blepharospasm, conjunctival chemosis, bilateral superficial punctate keratitis,

Copyright $(\subset 2017$ The Author(s). This is an open access article distributed under the terms of the Creative Commons Attribution License (http:// creativecommons.org/licenses/by/4.0), which permits unrestricted use, distribution, and reproduction in any medium, provided the original work is properly cited. 
and even corneal epithelial defects are signs of this disease. The severity of signs may develop in individuals with light skin or with pre-existing ophthalmological conditions such as dry eye disease, keratoconus, and refractive surgery.

\section{Management Strategy of Snow Blindness}

When snow blindness occurs, it is necessary to avoid additional exposure to UVR. Relief from symptoms occurs within 24 to 72 hours, depending on the degree of UVR exposure. ${ }^{8}$ Treatments include cooling compress, preservativefree lubricants, topical anti-inflammatory and cycloplegic medications, bandage contact lenses, ophthalmic antibiotic ointments, and systemic analgesics. ${ }^{9}$ Topical anesthetic drops must not be used because of slow corneal healing; moreover, they can cause corneal melting. ${ }^{10}$ The principle of managing snow blindness is prevention. People traveling to distant snow-covered areas or to high altitudes should wear appropriate UVR-filtering goggles or sunglasses with side shields. For maximum protection, these filters must have $\mathrm{CE} /$ EN protection class 3 or $4 .{ }^{11}$

\section{Dry Eye}

Dry eye is a complex condition characterized by red rye, foreign body sensation, burning, photosensitivity, and blurred vision, depending on the degree of dryness. ${ }^{12}$ Dry eye disease is exacerbated in the dry, windy, and sun glare conditions seen at high altitudes. ${ }^{13}$ Severe dry eye disease can be associated with some autoimmune disorders, and commonly-used medications can exacerbate ocular dryness. Systemic drugs with anticholinergic effects decrease tear production. These medications include alpha blockers, beta blockers, antidepressants, and atropine-like agents. Systemic cold treatments such as ephedrine, pseudoephedrine, and antihistamines, which are commonly used in cold environments and at high altitudes, can also decrease tear production. $^{2}$

\section{Management Strategy of Dry Eye}

The mainstay treatment for dry eye is artificial tears and lubricating ointment. In moderate to severe symptoms, preservative-free artificial tears should be used frequently, because the preservative material in ophthalmic drops can cause ocular irritation. ${ }^{2}$ In the severe form of ocular surface dryness, reversible punctal occlusion can be observed. Additional local treatments include the oral consumption of omega-3 fatty acids which can increase tear secretion, decrease the amount of tear evaporation, and improve the symptoms of dry eye disease. ${ }^{14}$ People with systemic disorders or eye dryness induced by the consumption of drugs should avoid high altitude environments. Decreased use of contact lens by people with dry eye syndrome is advised due to the risk of keratitis. Mountaineers may benefit from fitted goggles or wrap-around sunglasses. These devices can decrease tear evaporation, increase the humidity around the eyes, and thereby decrease the risk of developing symptoms of dry eye disease.

\section{Recurrent Corneal Erosion}

In low humidity situations and dry ocular surfaces such as high altitudes, people with previous corneal trauma, preexisting epithelial basement membrane dystrophy, a history of photorefractive keratectomy, or laser-assisted in situ keratomileusis may experience recurrent corneal erosion. ${ }^{15}$ Symptoms of this condition are a sudden onset of pain, tearing, and photophobia. Corneal defects can be seen with fluorescein drops and a penlight.

\section{Management Strategy of Recurrent Corneal Erosion}

Treatment for recurrent corneal erosion includes frequent use of preservative-free artificial drops and antibiotic ointment. To prevent this condition, people who have risk factors for this disorder should use lubricant and simple eye ointment.

2-Eye Problems Associated With Low-Pressure Environments High-Altitude Cortical Blindness

Cortical blindness was first described by Hackett et al in 1987 among trekkers in the Himalayas. It is characterized by transient blindness in both eyes with intact pupillary reflexes. Relative afferent pupillary defect is not seen. ${ }^{16}$ In addition, monocular blindness related to high altitude that affects one eye is amaurosis fugax. In this form of blindness, relative afferent pupillary defect is seen. These conditions occur suddenly and without prior signs or symptoms of acute mountain illness. ${ }^{17}$ The pathophysiology for both conditions may be a compromised blood supply to the visual cortex and the retina caused by vascular spasm of the central retinal artery in amaurosis fugax.

Management Strategy of High-Altitude Cortical Blindness Increased cerebral blood flow caused by oxygen inhalation or rebreathing carbon dioxide can improve the sign and symptoms of high-altitude cortical blindness. Also, descent can instigate the rapid recovery of visual function. ${ }^{16}$

\section{High-Altitude Ocular Dysmotility}

Lateral rectus palsy due to sixth nerve palsy at high altitude is well known at this time. Cranial nerve palsies, especially sixth nerve palsy, are associated with acute mountain sickness and high altitude cerebral edema; however, many times these nerve palsies have been reported with no preceding symptoms of high altitude sickness. ${ }^{18,19}$ A study on the largest series of high-altitude cerebral edema patients showed that cranial nerve palsies occurred in less than $1 \%$ of the 44 patients suffering from high altitude cerebral edema. ${ }^{20}$ Kramár et al revealed that convergence insufficiency due to a decrease in amplitude of convergence was found in women during their ascent of the Himalayas. Compared with young mountaineers, that amplitude of accommodation remained stable; this measurement was decreased in older people during ascents to higher altitudes. ${ }^{21}$

Management Strategy of High-Altitude Ocular Dysmotility Although this condition, especially when independent of high altitude cerebral edema symptoms, is often a benign prognosis, the improvement of diplopia and muscle palsy can last for several weeks up to months. ${ }^{22}$ Regardless of the causes, descent to low altitude may be the best treatment. ${ }^{16,18}$

\section{High-Altitude Retinopathy}

High-altitude retinopathy (HAR), first described by Singh et 
al. is a pathological retinal response to hypoxia. ${ }^{23}$ Fundoscopic features of this entity include retinal hemorrhages, retinal vessel tortuosity and dilation, optic disk swelling, anterior ischemic optic neuropathy, cotton wool spots, subhyaloid hemorrhage, vitreous hemorrhage, and even rhegmatogenous retinal detachment. ${ }^{24-31}$ Retinal vascular accidents related to HAR that included central retinal and branch retinal vein occlusion have been reported. ${ }^{32,33}$ Among these signs, retinal hemorrhages and vascular engorgement and tortuosity are more common. However, HAR is often asymptomatic, but when the macula is affected, vision may be reduced. ${ }^{34}$ The incidence rate of HAR varies between $3.8 \%$ and $90.5 \%$ with no preponderance in gender. ${ }^{35,36}$ Optic disk swelling happens frequently in mountaineers at high altitudes. The incidence rate of this condition among climbers varies from 59\% to $79 \%$ depending on the altitude above sea level and the speed of ascent. ${ }^{37,38}$ There is a correlation between optic disk swelling, low arterial oxygen saturation, and the signs and symptoms of acute mountain disease. Hypoxia-induced brain volume increase is considered the most common cause of disk swelling at high altitudes.

\section{Management Strategy of High-Altitude Retinopathy}

The pathophysiology of HAR is not clear, but the highest altitude achieved is considered as a risk factor. ${ }^{39}$ Patients with symptomatic HAR (especially impaired vision) should descend as soon as possible for more examinations and treatment. Symptomatic HAR is treated the same way as acute mountain sickness, with rest, oxygen, acetazolamide, and descent to a lower altitude. ${ }^{34}$ Descending to lowlands leads to the complete improvement of disk swelling. ${ }^{37}$

\section{3-Eye Problems Associated With Past Ocular or Medical Conditions \\ Glaucoma and High Altitudes}

The measurement of intraocular pressure (IOP) can be affected by anatomical, instrumental, and physiological error. Moreover, the effect and significance of altitude on IOP may be masked by several factors. ${ }^{34}$

There is a controversy about the effect of high altitude on IOP. Some groups have shown a decreased IOP, an increased IOP, a normal IOP, a reduction within hours of ascent, ${ }^{34}$ and recovery during acclimatization. ${ }^{40,41}$

High altitude causes a statistically significant, but clinically insignificant, increase in IOP. This finding may result from changes in central corneal thickness. ${ }^{42}$

\section{Management Strategy of Glaucoma at High Altitudes}

There is no data indicating that people with glaucoma cannot travel to high altitudes, but a full ophthalmologic examination before travel is recommended. ${ }^{34}$ Acetazolamide can be used for prophylaxis and the treatment of acute mountain sickness in glaucoma patients. ${ }^{34}$

\section{Refractive Surgery and High Altitude}

Subjects with radial keratotomy for correct myopia may be at risk for visual deterioration at high altitudes. ${ }^{43}$ Incisions made during this procedure weakens the cornea and eventually leads to deformation during exposure to hypoxic conditions. ${ }^{44}$ Hyperopic shift with deterioration has been reported at high altitudes. ${ }^{44-46}$

Management Strategy of Refractive Surgery Disorder at High Altitudes

Subjects who have had radial keratotomy to correct myopia should travel to high altitudes with corrective spectacles and varying degrees of hyperopia correction. ${ }^{2}$ The visual changes correct with descent or prolonged stays at the high altitude. ${ }^{47}$

\section{Retinal Surgery With Intraocular Gas and High Altitude}

Modern vitreoretinal surgical techniques frequently employ the introduction of a potentially expansile gas into the eye. ${ }^{48}$ The purpose of the gas is to hold the retina against the retinal pigment epithelium following cryopexy or laser retinopexy until a scar is formed between the retina and the underlying tissue around a retinal break. ${ }^{49}$

Travelers with intraocular gas are at risk of a clinically significant rise in IOP because the gas expands when exposed to reduced absolute pressure. ${ }^{50}$ Unlike air, this gas can expand after being injected into the eye and take much longer to be resorbed back into circulation. So, at reduced pressure, a gas bubble expands. ${ }^{51}$

The primary size of the intraocular bubble is an important factor for the peak IOP and the recovery from it after prolonged hypobaric exposure. ${ }^{52}$ This fact may lead to some suggestions that flying may be safe under certain circumstances, especially with small bubbles. ${ }^{49,52,53}$

\section{Management Strategy of Retinal Surgery With Intraocular} Gas at High Altitudes

Due to the influence of IOP, the production of anterior chamber fluid, choroidal perfusion, and the prediction of the time of bubble resolution can vary considerably. Therefore, a decision to travel to high altitudes should involve the treating surgeon. ${ }^{48}$

\section{Contact Lenses and High Altitudes}

Although contact lenses may be used safely at high altitudes, traveling may disrupt routine care, including cleaning, sterilizing, deproteinizing, and proper storage. ${ }^{2}$ Thus, their use is associated with an increased risk for corneal infections.

\section{Management Strategy of Contact Lenses at High Altitudes} Discomfort associated with the use of contact lenses may be resolved with the more frequent use of lubricant. Overnight usage of extended-wear contact lenses should be avoided. This is due to the fact that they are usually associated with an increased risk of corneal infections. ${ }^{2}$

\section{Diabetic Retinopathy and High Altitudes}

High altitude traveling can be associated with retinal hemorrhage, with a vast range of difficulties in assessing glycemic control. ${ }^{54}$ Blurring of vision can occur during hypoglycaemic situations. HAR related to hypoxia can occur at altitudes higher than 5000 meters. It is said that this usually resolves after 1-2 weeks, even in cases when patients remain at high altitudes. ${ }^{54,55}$

Management Strategy of Diabetic Retinopathy at High Altitudes Patients with diabetic retinopathy should finish the course of 
treatment prior to traveling. There is no clinical evidence that vitreous hemorrhages are more likely during travel. ${ }^{55}$

\section{Conclusion}

Individuals whose travels take them to high altitudes may experience some ocular problems, particularly disorders related to dry and cold environments. Physicians, especially ophthalmologists, should be knowledgeable in prevention techniques and treatments for these conditions. The main management for ocular disorders related to dry and cold environments include the use of eye shields and artificial tear drops. Descending to low-altitude lands is the key to management of eye problems associated with low-pressure environments. Patients with past ocular problems or ocular surgery should consult their doctors before ascending to high altitudes.

\section{Authors' Contributions}

All authors significantly contributed towards this study.

\section{Conflict of Interest Disclosures}

The authors have no conflicts of interest.

\section{Ethical Approval \\ Not applicable.}

\section{Funding/Support}

None.

\section{References}

1. Ellerton JA, Zuljan I, Agazzi G, Boyd JJ. Eye problems in mountain and remote areas: prevention and onsite treatment-official recommendations of the International Commission for Mountain Emergency Medicine ICAR MEDCOM. Wilderness Environ Med. 2009;20(2):169-175. doi:10.1580/08-WEME-REV-205R1.1.

2. Mader $\mathrm{TH}$, Tabin G. Going to high altitude with preexisting ocular conditions. High Alt Med Biol. 2003;4(4):419-430. doi:10.1089/152702903322616173.

3. Karaküçük S, Mirza GE, Rul G. Ophthalmological effects of high altitude. Ophthalmic Res. 2000;32(1):30-40.

4. Jokela K, Leszczynski K, Visuri R. Effects of Arctic ozone depletion and snow on UV exposure in Finland. Photochem Photobiol. 1993;58(4):559-566.

5. McKenzie RL, Johnston PV, Smale D, Bodhaine BA, Madronich S. Altitude effects on UV spectral irradiance deduced from measurements at Lauder, New Zealand, and at Mauna Loa Observatory, Hawaii. J Geophys Res. 2001;106(D19):2284522860 .

6. Meinander O, Kontu A, Asmi E, Sanchez R, Mei M, de Leeuw G. Bipolar high temporal resolution measurements of snow UV albedo in Sodankylä and Marambio. Paper presented at: EGU General Assembly Conference Abstracts; 2015.

7. Schein OD. Phototoxicity and the cornea. J Natl Med Assoc. $1992 ; 84(7): 579$.

8. Willmann G. Ultraviolet Keratitis: from the pathophysiological basis to prevention and clinical management. High Alt Med Biol. 2015;16(4):277-282. doi:10.1089/ham.2015.0109.

9. Blumthaler M, Ambach W, Daxecker F. On the threshold radiant exposure for keratitis solaris. Invest Ophthalmol Vis Sci. 1987;28(10):1713-1716.

10. Patel M, Fraunfelder FW. Toxicity of topical ophthalmic anesthetics. Expert Opin Drug Metab Toxicol. 2013;9(8):983-988. doi:10.151 7/17425255.2013.794219.

11. Morris DS, Evans S. Visual performance in extreme sports. In: Feletti F, ed. Extreme Sports Medicine. Springer; 2017:417-428.

12. Bartlett JD, Keith MS, Sudharshan L, Snedecor SJ. Associations

\section{Review Highlights}

\section{What Is Already Known?}

Exposure to cold and low-pressure environments during high altitude traveling poses risks for cold-related or pressure-related injury to eyes. Furthermore, some preexisting ophthalmologic conditions may be exacerbated by high-altitude exposure. Visual disturbances may result from exposure to the hypoxia of high altitudes.

\section{What This Study Adds?}

The main management for ocular disorders related to dry and cold environments include the use of eye shields and artificial tear drops. Descending to low-altitude lands is the key to management of eye problems associated with low-pressure environments. Patients with past ocular problems or ocular surgery should consult their doctors before ascending to high altitudes.

between signs and symptoms of dry eye disease: a systematic review. Clin Ophthalmol. 2015;9:1719-1730. doi:10.2147/OPTH. S89700.

13. Gupta N, Prasad I, Himashree G, D'Souza P. Prevalence of dry eye at high altitude: a case controlled comparative study. High Alt Med Biol.2008;9(4):327-334. doi:10.1089/ham.2007.1055.

14. Kangari $\mathrm{H}$, Eftekhari $\mathrm{MH}$, Sardari $\mathrm{S}$, et al. Short-term consumption of oral omega-3 and dry eye syndrome. Ophthalmology. 2013;120(11):2191-2196. doi:10.1016/j.ophtha.2013.04.006.

15. Diez-Feijóo E, Grau AE, Abusleme El, Durán JA. Clinical presentation and causes of recurrent corneal erosion syndrome: review of 100 patients. Cornea. 2014;33(6):571-575. doi:10.1097/ ICO.0000000000000111.

16. Basnyat B, Wu T, Gertsch JH. Neurological conditions at altitude that fall outside the usual definition of altitude sickness. High Alt Med Biol. 2004;5(2):171-179.

17. Dickinson J. Transient monocular amaurosis at high altitude. High Alt Med Biol. 2001;2(1):75-75.

18. Basnyat B, Cumbo TA, Edelman R. Acute medical problems in the Himalayas outside the setting of altitude sickness. High Alt Med Biol. 2000;1(3):167-174.

19. Virués-Ortega J, Buela-Casal G, Garrido E, Alcázar B. Neuropsychological functioning associated with high-altitude exposure. Neuropsychol Rev. 2004;14(4):197-224.

20. Dickinson JG. High altitude cerebral edema: Cerebral acute mountain sickness. Paper presented at: Seminars in Respiratory Medicine; 1983.

21. Kramár PO, Drinkwater BL, Folinsbee LJ, Bedi JF. Ocular functions and incidence of acute mountain sickness in women at altitude. Aviat Space Environ Med. 1983;54(2):116-120.

22. Murdoch DR. Lateral rectus palsy at high altitude. J Wilderness Med. 1994;5(2):179-181.

23. Singh I, Khanna P, Srivastava M, Lal M, Roy SB, Subramanyam C. Acute mountain sickness. N Engl J Med. 1969;280(4):175-184.

24. Frayser R, Houston CS, Bryan AC, Rennie ID, Gray G. Retinal hemorrhage at high altitude. N Engl J Med. 1970;282(21):11831184.

25. Rennie D, Morrissey J. Retinal changes in Himalayan climbers. Arch Ophthalmol. 1975;93(6):395-400.

26. Shults WT, Swan KC. High altitude retinopathy in mountain climbers. Arch Ophthalmol. 1975;93(6):404-408.

27. Wiedman M. High altitude retinal hemorrhage. Arch Ophthalmol. 1975;93(6):401-403.

28. McFadden DM, Houston CS, Sutton JR, Powles AP, Gray GW Roberts RS. High-altitude retinopathy. JAMA. 1981;245(6):581586.

29. Hanifudin A, Lim LT, Ah-Kee EY, El-Khashab T. High altitude subhyaloid hemorrhage. Oman J Ophthalmol. 2015;8(3):213. 
30. Morris DS, Severn PS, Smith J, Somner JE, Stannard KP, Cottrell DG. High altitude and retinal detachment. High Alt Med Biol. 2007;8(4):337-339.

31. Bandyopadhyay S, Singh R, Gupta V, Gupta A. Anterior ischaemic optic neuropathy at high atitude. Indian J Ophthalmol. 2002;50(4):324.

32. Butler FK, Harris DJ, Reynolds RD. Altitude retinopathy on Mount Everest, 1989. Ophthalmology. 1992;99(5):739-746.

33. Arora R, Jha K, Sathian B. Retinal changes in various altitude illnesses. Singapore M J. 2011;52(9):685-688.

34. Morris DS, Mella S, Depla D. Eye problems on expeditions. Travel medicine and infectious disease. 2013;11(3):152-158.

35. Wiedman M, Tabin GC. High-altitude retinopathy and altitude illness. Ophthalmology. 1999;106(10):1924-1927.

36. Clarke C, Duff J. Mountain sickness, retinal haemorrhages, and acclimatisation on Mount Everest in 1975. Br Med J. 1976;2(6034):495-497.

37. Bosch MM, Barthelmes D, Merz TM, et al. High incidence of optic disc swelling at very high altitudes. Arch Ophthalmol. 2008;126(5):644-650. doi:10.1001/archopht.126.5.644.

38. Willmann G, Fischer MD, Schatz A, et al. Quantification of optic disc edema during exposure to high altitude shows no correlation to acute mountain sickness. PLoS One. 2011;6(11):e27022. doi:10.1371/journal.pone.0027022.

39. Morris DS, Somner J, Donald MJ, et al. The eye at altitude. Hypoxia and Exercise. Springer; 2006:249-270.

40. Pavlidis M, Stupp T, Georgalas I, Georgiadou E, Moschos M, Thanos S. Intraocular pressure changes during highaltitude acclimatization. Graefes Arch Clin Exp Ophthalmol. 2006;244(3):298-304.

41. Cymerman A, Rock PB, Muza SR, et al. Intraocular pressure and acclimatization to $4300 \mathrm{M}$ altitude. Aviat Space Environ Med. 2000;71(10):1045-1050.

42. Somner JE, Morris DS, Scott KM, MacCormick IJ, Aspinall P, Dhillon B. What happens to intraocular pressure at high altitude? Invest Ophthalmol Vis Sci. 2007;48(4):1622-1626. doi:10.1167/ iovs.06-1238.

43. Mieske K, Flaherty G, O'Brien T. Journeys to high altitude—risks and recommendations for travelers with preexisting medical conditions. J Travel Med. 2010 n;17(3):214. doi:10.1111/j.17088305.2010.00414.x

44. Winkle RK, MaderTH, Parmley VC, White LJ, Polse KA. The etiology of refractive changes at high altitude after radial keratotomy: hypoxia versus hypobaria. Ophthalmology. 1998;105(2):282-286.

45. Mader $\mathrm{TH}$, Blanton $\mathrm{CL}$, Gilbert $\mathrm{BN}$, et al. Refractive changes during 72-hour exposure to high altitude after refractive surgery. Ophthalmology. 1996;103(8):1188-1195.

46. Mader TH, White LJ, Johnson DS, Barth FC. The ascent of Mount Everest following radial keratotomy. Wilderness \& Environmental Medicine. 2002;13(1):53-4.

47. Wilson DF, Roy A, Lahiri S. Immediate and long-term responses of the carotid body to high altitude. High Alt Med Biol. 2005;6(2):97111.

48. Houston S, Graf J, Sharkey J. Commercial air travel after intraocular gas injection. Aviat Space Environ Med. 2012;83(8):809-810.

49. Levasseur SD, Rahhal FM. Travel to high mountain elevations following vitrectomy with intraocular gas. Retina. 2013;33(7):14561461. doi:10.1097/IAE.0b013e318280766f.

50. Kokame GT, Ing MR. Intraocular gas and low-altitude air flight. Retina. 1994;14(4):356-358.

51. Lincoff $\mathrm{H}$, Weinberger $\mathrm{D}$, Reppucci $\mathrm{V}$, Lincoff $\mathrm{A}$. Air travel with intraocular gas: I. The mechanisms for compensation. Arch Ophthalmol. 1989;107(6):902-906.

52. Mills MD, Devenyi RG, Lam W-C, Berger AR, Beijer CD, Lam SR. An assessment of intraocular pressure rise in patients with gas-filled eyes during simulated air flight. Ophthalmology. 2001;108(1):4044 .

53. Lincoff $\mathrm{H}$, Weinberger D, Stergiu P. Air travel with intraocular gas: II. Clinical considerations. Arch Ophthalmol. 1989;107(6):907910.

54. Moore K, Vizzard N, Coleman C, McMahon J, Hayes R, Thompson C. Extreme altitude mountaineering and type 1 diabetes; the Diabetes Federation of Ireland Kilimanjaro Expedition. Diabet Med. 2001;18(9):749-755.

55. Leal C, Admetlla J, Viscor G, Ricart A. Diabetic retinopathy at high altitude. High Alt Med Biol. 2008;9(1):24-27. 